\title{
Ultra-wideband MMICs for remote sensing applications
}

Johansen, Tom Keinicke; Vidkjær, Jens; Krozer, Viktor

Published in:

33rd European Microwave Conference, 2003.

Link to article, DOI:

10.1109/EUMA.2003.341094

Publication date:

2003

Document Version

Publisher's PDF, also known as Version of record

Link back to DTU Orbit

Citation (APA):

Johansen, T. K., Vidkjær, J., \& Krozer, V. (2003). Ultra-wideband MMICs for remote sensing applications. In 33rd European Microwave Conference, 2003. IEEE. https://doi.org/10.1109/EUMA.2003.341094

\section{General rights}

Copyright and moral rights for the publications made accessible in the public portal are retained by the authors and/or other copyright owners and it is a condition of accessing publications that users recognise and abide by the legal requirements associated with these rights.

- Users may download and print one copy of any publication from the public portal for the purpose of private study or research.

- You may not further distribute the material or use it for any profit-making activity or commercial gain

- You may freely distribute the URL identifying the publication in the public portal

If you believe that this document breaches copyright please contact us providing details, and we will remove access to the work immediately and investigate your claim. 


\title{
Ultra-wideband MMICs for remote sensing applications
}

\author{
Tom K. Johansen, Jens Vidkjær, Viktor Krozer, \\ Technical University of Denmark, Oersted-DTU, Department of Electromagnetic Systems, \\ Oersteds Plads 348, 2800 Kgs. Lyngby, Denmark, Phone:+45-45253770, E-mail:tkj@oersted.dtu.dk
}

\begin{abstract}
This paper presents an overview of the current activity at the Technical University of Denmark in the field of ultra-wideband monolitic microwave integrated circuits (MMICs) for next-generation high-resolution synthetic aperature radar (SAR) systems. The transfer function requirements for MMIC components in a wideband SAR systems are described. The design and performance of a DC-to-X-band SiGe HBT quadrature mixer and a C-band GaAs pHEMT downconverter are described. Experimental results demonstrates the usefulness of the designs for quadrature modulation/demodulation and downconversion of ultra-wideband linear FM-modulated signals.
\end{abstract}

\section{INTRODUCTION}

At the Technical University of Denmark, research in SAR systems have been performed for several years. A fully polarimetric and interferometric L- and C-band SAR system, known as EMISAR, has been developed and operated during airborne campaigns [1]. A technology program denoted SAR++ is ongoing at the Technical University of Denmark aiming at developing the technologies and know-how needed to design the next generation civilian SAR systems. The design goals is a multi-frequency, polarimetric, SAR system with a instantaneous bandwidth of up to $800 \mathrm{MHz}$ depending on carrier frequency and thus achievable antenna bandwidth and frequency restriction [2].

To get high-performance in next generation SAR systems technologies like multi-chip modules (MCMs) and monolithic microwave integrated circuits (MMICs) seems promising for implementing critical subsystems. In particular the small size, wideband performance, and flexible circuit design available with MMIC technology is required for SAR systems.

In this paper various aspect of ultra-wideband MMIC design for next generation SAR systems are described. First the sensor configuration considered in the SAR++ system is described followed by a discussion of the transfer function requirements set by the impulse response parameters specification. Next the design and performance of a DC-to-X-band SiGe HBT quadrature mixer design is described. The quadrature mixer was implemented in a $0.8 \mu \mathrm{m}, 35 \mathrm{GHz} f_{T}$ SiGe HBT process and achieved 3dB RF- and IF-port bandwidths of 11 $\mathrm{GHz}$ and $7.5 \mathrm{GHz}$ respectively making it suiteble for modulation/demodulation of ultra-wideband linear FM-modulated signals. Finally the design and performance of a C-band GaAs pHEMT downconverter is discussed. The downconverter was implemented in a $0.2 \mu \mathrm{m}, 63 \mathrm{GHz} f_{T}$ GaAs pHEMT process and demonstrates flat conversion gain at C-band over an 800 $\mathrm{MHz}$ bandwidth with fixed LO frequency.

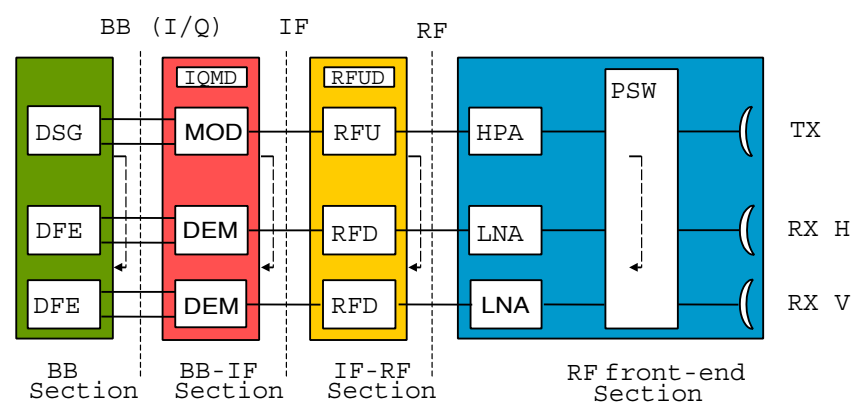

Fig. 1. Sensor Configuration for the SAR++ system. In a homodyne architechture the IF-RF section is omitted. The transmitting antenna (TX) and two receiving antennas ( $\mathrm{RX} \mathrm{H}$ and $\mathrm{RX} \mathrm{V}$ ) is physical one single dual polarized antenna.

\section{WIDEBAND SAR SYSTEM}

\section{A. System Overview}

In Fig. 1 the sensor configuration considered in the SAR++ system is shown. Different frequency bands (L-, C-, and Xband) require different sensor configurations. A single channel is used on the transmit side to generate the linear FMmodulated signal around the microwave carrier. Multiple channels are needed on the receive side (only two shown in Fig. 1) to be able to implement polarimetry and interferometry, Each sensor consist of a number of sections. The baseband section (BB Section) contains the digital signal generator (DSG) that generates the I/Q baseband signals, and the digital front end (DFE) that converts the demodulated I/Q baseband signals to digital form. The BB-IF section contains the quadrature modulator converting the I/Q baseband signals to IF and the quadrature demodulator converting the IF to baseband. Frequency conversion from IF to RF, and RF to IF are performed in the IF-RF section by the RF upconverter and downconverter, respectively. In a homodyne architechture the IF-RF section is omitted and the baseband signal is directly modulated and demodulated on the radiated microwave carrier. For wideband SAR applications the homodyne technique has certain advantages compared with the conventional heterodyne technique [3]. Most important is the reduced complexity and fewer bandwidth limiting components. Finally, the RF front-end section contains the high power amplifier (HPA) generating the desired RF power level, the low noise amplifiers (LNAs), polarization and T/R switch (PSW), and the (multifrequency, dual polarized) antenna. The modular design approach ensures that adding an additional frequency band (Ku-band or higher) only requires limited redesign. 


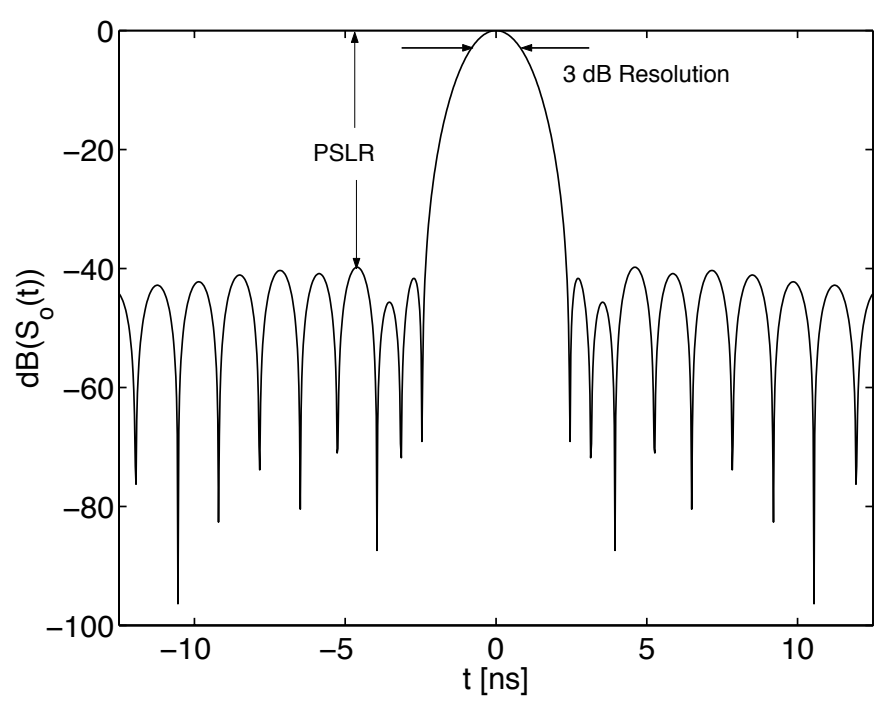

Fig. 2. Impulse response for ideal pulse compression SAR system.

\section{B. Distortion in Pulse Compression SAR System}

To achieve high resolution and acceptable sensitivity in a SAR system, a linear FM-modulated pulse of long duration is often transmitted. The high resolution is achieved by pulse compression of the received echo signal. The pulse compression is performed by matched filtering in the receiver. A compressed pulse with main lobe width $1 / B$ results, where $B$ is the bandwidth of the transmitted linear-FM modulated pulse. In a pulse compression SAR system the basic requirements are related to the impulse response obtained from a point target. The point target parameters of interest are the $3 \mathrm{~dB}$ resolution, peak side-lobe ratio (PSLR), and integrated sidelobe ratio (ISLR). The impulse response is the output of the matched filter due to the received echo and includes the effect of distortion due to non-ideal components in the receiver and transmitter. Fig. 2 shows the impulse response from a point target in an ideal SAR system. The spectrum of the received echo is Hamming weighted in order to suppress the large sidelobes due to the uniform amplitude characteristic of the linear FM-modulated signal. The $3 \mathrm{~dB}$ resolution is the width of the main lobe at half the maximum value as illustrated in Fig. 2 , and is a measure of the minimum discernible detail of the image. The peak side-lobe ratio (PSLR) is the ratio of the main lobe of the impulse response to the peak side-lobe level. The PSLR is a measure of the ability of the radar to detect weak reflective targets in the proximity of a strong reflective target. The integrated side-lobe ratio (ISLR) is the ratio of the energy in the side-lobes to the energy in the main lobe. ISLR is a measure of the attainable contrast in the image.

The point target parameters for a pulse compression SAR system are degraded by signal distortion occuring anywhere in the system [2]. Signal distortion occurs whenever the amplitude response is not flat and the signal delay is not constant over the bandwidth of the signal. The result is a reduced resolution and increased side-lobe levels. The transfer function distortion can be divided into three models describing periodic distortion (ripples), random distortion, and slowly varying distortion. Ripples will cause unwanted side-lobes (one side-lobe before and one after the main lobe) in the timedomain and degrade the PSLR of the SAR system. The ripples may result from non-ideal design or multiple reflections along mismatched transmission line. The transfer function of real components often exhibits more complex behavior described as random distortion which degrade the ISLR performance. The last form of transfer function distortion is due to lowfrequency phase errors. Low-frequency phase errors are caused by dispersive components including ripple components with less than one cycle over the signal bandwidth. The result is a broadening of the main lobe and an increase in the sidelobe level. In Table I a summery of transfer function requirements for the $\mathrm{SAR}++$ system which require $P S L R=$ $-30 d B$ and $I S L R=-18 d B$ are given. It is noticed that the point target parameters translate into stringent transfer function requirement for the SAR system. To assure that the total system fulfill the point target requirements the degradation due to the individual components in the SAR should be neglectible. It is thus a prerequisite that MMIC components for SAR applications exhibits wideband performance with high degree of gain flatness and phase linearity.

\begin{tabular}{|l|c|c|}
\hline \multirow{2}{*}{ Parameter } & \multicolumn{2}{|c|}{ Requirement } \\
\cline { 2 - 3 } & PSLR=-30dB & ISLR=-18dB \\
\hline Amplitude, Ripple [dB] & 0.27 & - \\
\hline Phase, Ripple [Deg.] & 1.8 & - \\
\hline Amplitude, RMS [dB] & - & 0.53 \\
\hline Phase, RMS [Deg.] & - & 3.6 \\
\hline Slow Phase Error [Deg.] & - & $60-90$ \\
\hline
\end{tabular}

TABLE I

SUMMARY OF TRANSFER FUNCTION REQUIREMENTS FOR THE SAR++ SYSTEM (FROM [2]).

\section{DC-TO-X-BAND SiGE HBT QUADRATURE MIXER DESIGN}

The Gilbert Cell mixer topology [4] is usually preferred for monolithic integration due to its high conversion gain over a broad frequency band, and good port-to-port isolation. Good microwave performance has been reported for Gilbert Cell mixers implemented in InP HBT [5], SiGe HBT [6], GaAs HBT [7] and GaAs pHEMT [8] technologies. SiGe HBT technology has been identified as a suitable technology for implementing the quadrature modulator/demodulator MMICs for SAR applications. Among the consideration have been the possibility of prototyping in small quantities as well as the high-level of integration offered with SiGe HBT technology.

\section{A. Circuit Design}

The schematic of a wideband SiGe HBT quadrature mixer design is shown in Fig. 3. The Gilbert Cell mixer is modified for wideband performance by means of emitter degeneration with capacitive peaking for the transconductance stage $\left(Q_{1}-\right.$ $\left.Q_{2}\right)$ and a shunt feedback stage $\left(Q_{7}-Q_{8}\right)$ for the load circuit. The transconductance stage with emitter degeneration allows a significant extension of the RF port bandwidth and can be optimized for conversion gain flatness and phase linearity. The shunt feedback stage provides a low impedance at the output node of the Gilbert Cell mixer which increases the IF port bandwidth. Furthermore, the transfer function of the shunt feedback stage may exhibit two complex conjugated poles with possible improvement in IF port bandwidth by high-frequency peaking. The design follows the principle of strong impedance mismatch between succeeding stages [9]. This principle is 


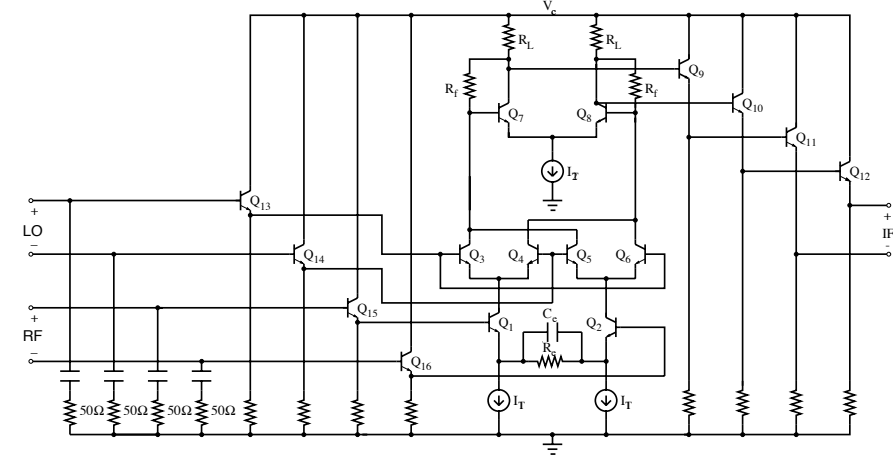

Fig. 3. Wideband SiGe HBT quadrature mixer with emitter degeneration of transconductance stage and shunt feedback load circuit.

beneficial for wideband circuit design for several reasons. First the influence from the frequency dependent input and output impedances are reduced. Secondly all internal circuit nodes are low impedance meaning reduced influence from parasitic capacitances. Finally, at high frequency where the mismatch is degraded, the input and output impedances approach complex conjugated pairs further extending the bandwidth. The emitter followers are included for improved mismatch between succeeding stages as well as level shifting and buffering. Impedance match at the RF and LO port is provided by accoupled $50 \Omega$ shunt resistors.

\section{B. Experimental Results}

The wideband quadrature mixer was implemented in a $0.8 \mu \mathrm{m}, 35 \mathrm{GHz} f_{T} \mathrm{SiGe}$ HBT process. The chip size including pads is $0.9 \times 0.9 \mathrm{~mm}^{2}$ and the power consumption is $170 \mathrm{~mW}$. When both RF and LO ports are swept in frequency with a fixed IF frequency of $0.4 \mathrm{GHz}$, a conversion gain of $8.5 \mathrm{~dB}$ and a $3 \mathrm{~dB}$ RF port bandwidth of $11 \mathrm{GHz}$ was achieved as shown in Fig. 4. A $3 \mathrm{~dB}$ IF port bandwidht of $7.5 \mathrm{GHz}$ was achieved when both RF and IF port swept in frequency with the LO frequency fixed at $2 \mathrm{GHz}$ as shown in Fig. 5. The frequency responses for the quadrature mixer are very well predicted by simulations. The good agreement is a result of accurate high-frequency modeling of SiGe HBT devices and substrate effects associated with interconnetion lines and pads structures. The equivalent circuit models have been extracted from on-wafer test structures in the $0.8 \mu \mathrm{m}$ SiGe HBT process and used in the simulation of the quadrature mixer. The large $\mathrm{RF}$ and IF port bandwidths makes the SiGe HBT quadrature mixer useful for modulation/demodulation of ultra-wideband linear FM-modulated signals.

\section{C-BAND GAAS PHEMT DOWNCONVERTER DESIGN}

GaAs pHEMT technology has been chosen for implementing the RF up/downconverters for SAR applications due to the good microwave performance of the transistors in pHEMT technology along with the possibility of prototyping in small quantities. Here a highly integrated C-band GaAs pHEMT downconverter design for SAR applications is reported. The downconverter design includes active baluns on the RF and LO ports and an active combiner circuit on the IF port of the Gilbert Cell Mixer.

\section{A. Circuit Design}

An active balun for the GaAs pHEMT downconverter should in addition to the usual requirements on gain flatness

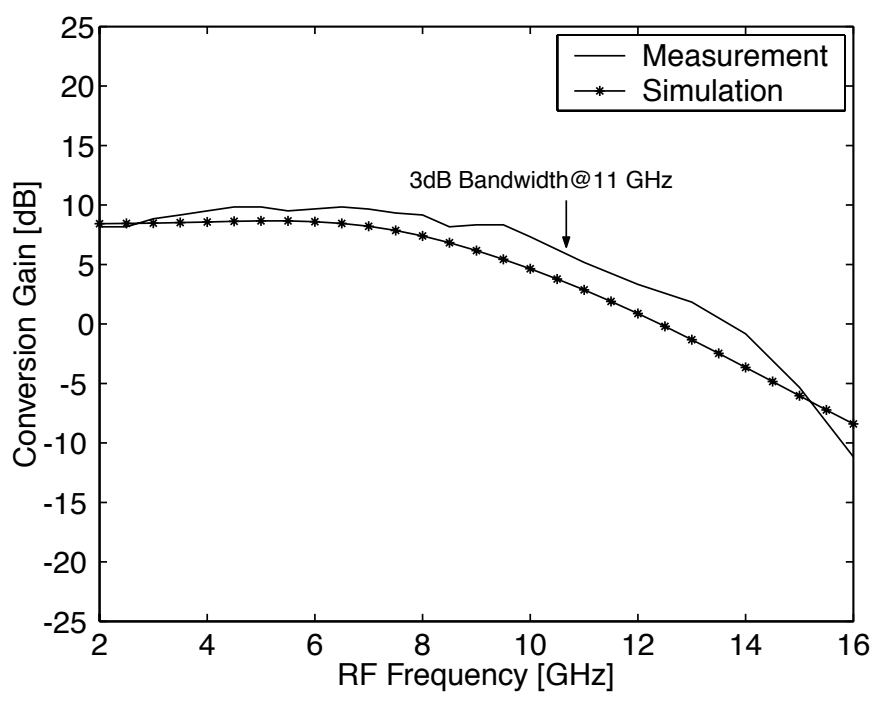

Fig. 4. Comparison of measured and simulated RF bandwidth limitation.

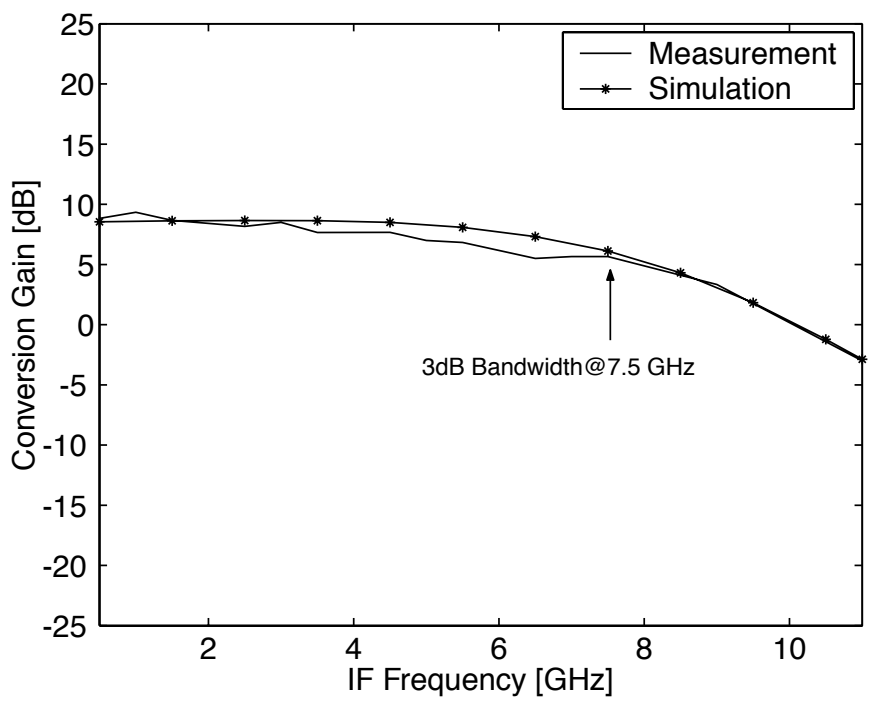

Fig. 5. Comparison of measured and simulated IF bandwidth limitation.

and phase linearity exhibit good wideband impedance match, low noise figure and low gain and phase imbalance. The gain and phase imbalance variations over the frequency range of interest should also be low in order to prevent transfer function distortion. A schematic of an active balun design based on the FET phase inverter configuration [10] is shown in Fig. 6. A FET device in a common-gate configuration provides wideband active impedance match to $50 \Omega$. An peaking inductance is included in series to the gate of the phase inverter FET to extend the usable frequency range for the active balun. The value of this inductance is carefully optimized for gain flatness and phase linearity. A transmission line following the source output of the phase inverter FET implements a phase adjustment circuit.

In Fig. 7 a schematic of the Gilbert cell mixer and an active output combiner circuit is shown. Inductors are added in series with the load resistors of the Gilbert Cell mixer to compensate the high-frequency degradation of the conversion gain due to capacitive loading at the output. This compensation technique is useful in the GaAs pHEMT Gilbert Cell mixer because of the high self-resonance frequency of the inductors available in this technology. An active combiner is needed 


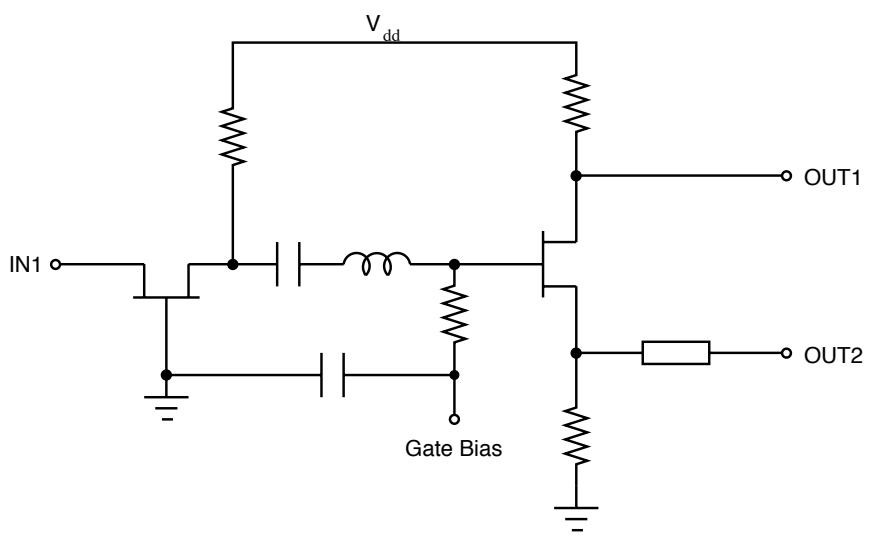

Fig. 6. Active balun based on the FET phase inverter configuration.

at the output of the Gilbert Cell mixer in order to prevent the LO leakage, caused by LO balun imperfections, from reaching the output port. An active combiner design based on source follower stages and a differential amplifier output stage is shown in Fig. 7. Level shift diodes are inserted in the source follower stages to provide the necessary bias for the differential amplifier stage. The series resistance components of the level shift diodes degrades the frequency response of the source follower stages. Therefore a capacitor is shunted across the diodes to provide a short for the high-frequency signal. This permits an increase in high-frequency gain and expansion of the bandwidth. The differential amplifier stage is degenerated with source resistors for increased linearity and wideband operation. An open drain arrangement is used at the output because this allows for the beneficial use of the bond inductance for further extension of the output port bandwidth.

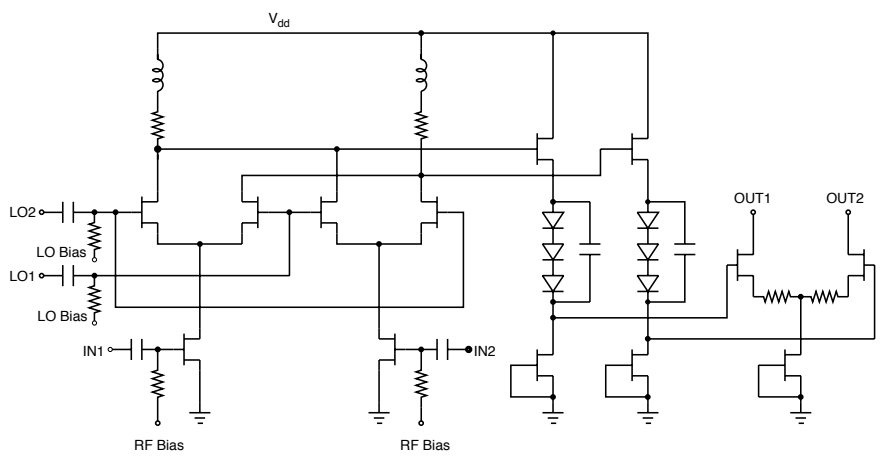

Fig. 7. Gilbert Cell mixer with reactive load and active output combiner.

\section{B. Experimental Results}

The designed C-band downconverter has been implemented in a $0.2 \mu \mathrm{m}, 63 \mathrm{GHz} f_{T}$ GaAs pHEMT process. The chip size is $1.5 \times 2.0 \mathrm{~mm}^{2}$ and the power consumption is $320 \mathrm{~mW}$. In order to demonstrate the usefulness of the designed GaAs pHEMT donwconverter for ultra-wideband SAR applications, the conversion gain was measured versus RF frequency with fixed LO frequency at $6.65 \mathrm{GHz}$ as shown in Fig. 8. The conversion gain is at approximately $10 \mathrm{~dB}$ with excellent flatness over an $800 \mathrm{MHz}$ bandwidth.

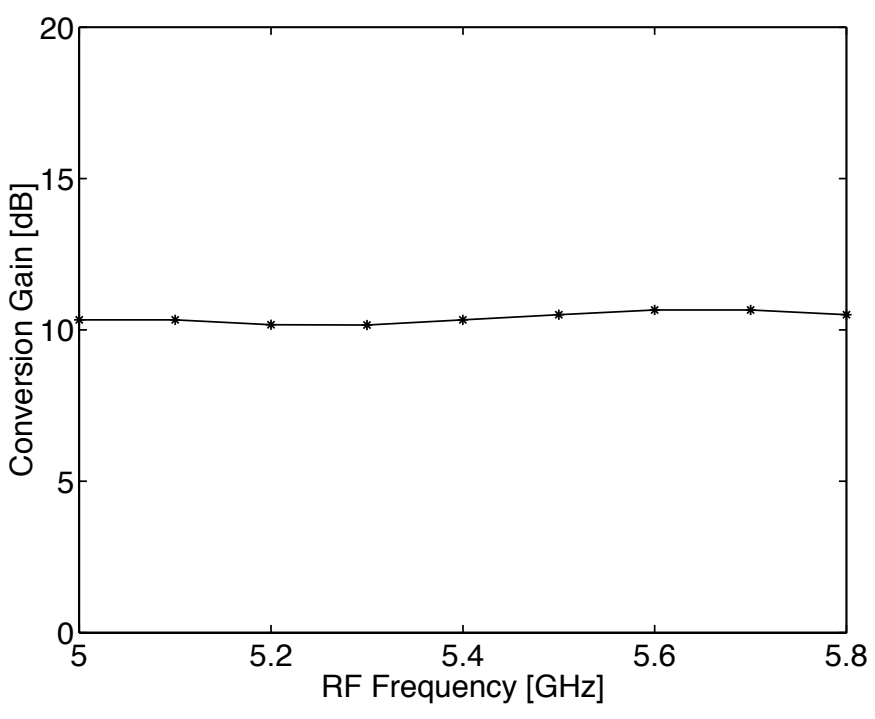

Fig. 8. Demonstration of C-band RF downconversion.

\section{Conclusions}

The design and performance of a DC-to-X-band SiGe HBT quadrature mixer and a C-band GaAs pHEMT downconverter for SAR applications have been shown. Experimental results demonstrates the usefulness of the designs for quadrature modulation/demodulation and downconvertion of ultra-wideband linear FM-modulated signals.

\section{ACKNOWLEDGEMENT}

The authors wish to acknowledge the support of the Danish Technical Research Council (STVF) under the SAR++ framework program.

\section{REFERENCES}

[1] E. Linzt Christensen, N. Skou, J. Dall, K. Woelders, J. H. Jorgensen, J. Granholm and S. N. Madsen, "EMISAR: An Absolutely Calibrated Polarimetric L- and C-band SAR", IEEE Trans. Geoscience and Remote Sensing, vol. 36, no. 6, pp. 1852-1865, Nov. 1998.

[2] E. Linzt Christensen (ed), SAR++ System Design Report, Technical Report R. 693, Technical University of Denmark, Dept. of Electromagnetic Systems, Jan 2000.

[3] E. Linzt Christensen, S. N. Madsen and N. Skou, "Review of the Homodyne Technique for Coherent Radar," IEEE Int. Radar Conference, 1990, pp. 159-163.

[4] B. Gilbert, "A Precise Four-Quadrant Multiplier with Subnanosecond Response,", IEEE Jour. Solid-State Circuits, SC.3, no. 4, pp. 373-380, Dec. 1968.

[5] K. W. Kobayashi et al., "A DC-20GHz InP HBT Balanced Analog Multiplier for High-Data-Rate Direct-Digital Modulation and Fiber-Optic Receiver Applications", IEEE Trans. Microwave Theory and Techniques, vol. 48, no. 2, pp. 194-202, Feb. 2000.

[6] J. Glenn et al., "12-GHz Gilbert Mixers using a Manufacturable Si/SiGe Epitaxial-Base Bipolar Technology”, IEEE BCTM, pp. 186-189, 1995.

[7] K. Osafune, "20-GHz 5-dB-Gain Analog Multipliers with AlGaAs/GaAs HBTs,", IEEE Trans. Microwave Theory and Techniques, vol. 42, no. 3, pp. 518-520, Mar. 1994

[8] C. F. Campbell and J. M. Beall, "Design and Performance of a Highly Integrated Wideband Active Downconverter MMIC,", IEEE Radio Frequency Integrated Circuits Symp., 2001.

[9] H.-M. Rein and M. Moller, "Design Considerations for Very-High-Speed Si-Bipolar ICs Operting up to $50 \mathrm{~GB} / \mathrm{s}, "$, IEEE Jour. Solid-State Circuits, vol. 31, no. 8, pp. 1076-1090, Aug. 1996

[10] H. Kamitsuna and H. Ogawa , "Ultra-Wideband MMIC Active Power Splitters with Arbitrary Phase Relationships,", IEEE Trans. Microwave Theory and Techniques, vol. 41, no. 9, pp. 1519-1523, Sept. 1993. 